\title{
Using the Project Method during the Graphic Training of Future Computer Science Teachers
}

\author{
Andrii Hedzyk ${ }^{1}$, Andrii Shuliak ${ }^{2, *}$, Andrii Hedzyk ${ }^{3}$ \\ ${ }^{1}$ Department of Vocational Education and Technology Profiles, Pavlo Tychyna Uman State Pedagogical University, Ukraine \\ ${ }^{2}$ Department of Pedagogics and Educational Management, Pavlo Tychyna Uman State Pedagogical University, Ukraine \\ ${ }^{3}$ Faculty of Engineering and Pedagogical Education, Pavlo Tychyna Uman State Pedagogical University, Ukraine
}

Received September 25, 2020; Revised November 23, 2020; Accepted December 4, 2020

\section{Cite This Paper in the following Citation Styles}

(a): [1] Andrii Hedzyk, Andrii Shuliak, Andrii Hedzyk, "Using the Project Method during the Graphic Training of Future Computer Science Teachers," Universal Journal of Educational Research, Vol. 8, No. 12A, pp. 7733 - 7740, 2020. DOI: 10.13189/ujer.2020.082560.

(b): Andrii Hedzyk, Andrii Shuliak, Andrii Hedzyk (2020). Using the Project Method during the Graphic Training of Future Computer Science Teachers. Universal Journal of Educational Research, 8(12A), 7733 - 7740. DOI: 10.13189/ujer.2020.082560.

Copyright $\odot 2020$ by authors, all rights reserved. Authors agree that this article remains permanently open access under the terms of the Creative Commons Attribution License 4.0 International License

\begin{abstract}
In view of the modern prospects of technological development, the role of a computer science teacher in providing comprehensive and competitive training to students of higher education institutions should not be underrated. As long as graphic technology constitutes, an essential part of every day changing information environment, graphic training must be paid, especially great attention and the methods for its performance must be thought-through deeply enough. The task of higher education institutions is not only to form the knowledge of the basic rules of performing graphic documents for future specialists but also to teach them how to use their knowledge for rational perception and transformation of the surrounding technology-related environment. The experience of the conducted research proved that an effective tool for the implementation of this goal is the use of the project method in the educational process, which in turn makes it necessary to justify the method of its use. This study revealed the features of using the project method at various stages of forming graphic concepts in the process of professional training of future computer science teachers. It is possible to conclude that in the project activity combined with the tasks of graphic training, future teachers of computer science comprehend the entire technology of solving problems from the problem statement to the presentation of the result.
\end{abstract}

Keywords Graphic Training, Project Method, Design
Stages, Computer Science Teachers, Formation Of Graphic Concepts

\section{Introduction}

At the present stage of development of society, the language of graphic images is becoming more widespread as a means of communication in many areas of professional (and not only) activities. Considering various problems of professional training of future teachers of computer science, one of the important issues is graphic training because lacking the knowledge of the basic graphic concepts makes impossible on the basis of analysis, calculations and other methods to ensure the creation, transformation or maintenance of technical, technological and other systems with specified parameters of their functioning [1-3].

In modern times, along with verbal ones, graphic means of transmitting information have acquired great importance: schemes, diagrams, drawings, sign models, cryptograms, and so on. An increasingly characteristic feature of any production is the indirect nature of managing existing technical objects and technological processes, that is, employees do not deal with real objects, but with their substitutes in the form of panels or control consoles, which indirectly, through systems of graphic 
images, graphic conventions and symbols, display real processes and phenomena. Existing graphic disciplines are associated with the formation of students' skills to perform drawings and are considered as a prerequisite for further professional training, which is associated with graphic knowledge and skills. There is a contradiction between the increasing role of graphic information in the life of society and the insufficient use of the potential of graphic educational disciplines for the development of mental operations as elements of the graphic culture of students [4].

Overall, the structure of an individual's psychological readiness for professional activity includes the following components: motivational (psychological attitude for situational readiness, interest in the activity, the subject's attitude to this activity, the need to achieve success); cognitive and operational (knowledge about the subject and methods of activity, understanding own responsibilities, tasks, assessment of their significance, knowledge of means to achieve goals); emotional (sense of responsibility, confidence in success); will-driven (self-management, focus on the task, as well as professionally important personal qualities and professional self-awareness) [5].

It is the teacher's readiness to implement new educational technologies that is an important factor in innovative changes in the organization of the educational process in higher education institutions. The practice of innovative technologies is quite diverse, and thus for their implementation in the educational process, the best option should be the one that focuses on problem-based and developmental training, a combination of front-line, group and individual forms of work, including a set of problematic and research methods of training [6].

In pedagogics, innovative activity is understood as the purposeful pedagogical activity based on understanding (reflection) of one's own practical experience by comparing and studying, changing and developing the educational process in order to achieve higher results, obtain new knowledge, and qualitatively different pedagogical practice. Accordingly, combining the concepts of educational and scientific innovations, the innovative activity of a teacher will be called the activity of transforming new knowledge and ideas into pedagogical technologies, introducing them into the content of education, and teaching tools [7].

The main functions of innovative activities include changing the components of the pedagogical process: goals, the content of education, forms, methods, technologies, learning tools, management systems, and so forth. Distinctive features of the innovative activity of a teacher are as follows [8]:

- Novel approach to setting goals and tasks;

- Deep content-richness;

- Unique, novel way of the use of previously known methods and use of new methods of solving pedagogical problems;
- Development of new concepts, the content of the activity, pedagogical technologies on the basis of humanization and individualization of the educational process;

- Ability to consciously change and develop oneself, to contribute to the profession.

Modern requirements imposed by society to a future computer science teacher make it necessary to strengthen graphic education, which is a part of the general and professional education of a specialist. In this regard, graphic education should be considered from the position of sufficiency to adapt the graduate to the circumstances of life and work in modern society [9].

Depending on the focus of the content part, graphics can be divided into technical, scientific, artistic, business, and so forth. The language of graphics is spoken in all countries by engineers, inventors, architects, designers, artists, and many other international representatives of professions, both humanitarian and technical. The language of graphics is international, professionally useful and practically necessary for every modern person. Objects of graphic representation can be various creations of human and nature. The role of graphics in various professional areas of human activity increases with the development and use of computer technology. The information provided graphically is also highly organized, as is the language [10]. For the graphic language has no international borders and is equally understandable to all people, regardless of what language they speak. The graphic language is much easier to adapt to the computer to understand it. Any graphic information is more specific, expressive, and concise than verbal information [11].

It is known that visual-imaginative thinking keeps a close relationship with practical actions; thus, in the activities of production sector workers, it takes the form of visual-active thinking. L. Itelson indicated that the technical image is inextricably linked with the concepts of perception, representation, imagination, memory, and logical thinking. Therefore, in the process of solving technical problems, the subject's representations and technical images are transformed in memory, as well as memory images are transformed [12]. In this regard, researchers consider the analogy to similarity, adjacency, contrast, and association to be one of the universal mechanisms of visual and imaginative thinking.

Modern computer graphics editors and computer systems allow shifting the emphasis in the graphic training of students towards the strengthening its modelling aspect, open up fundamentally new opportunities for analyzing graphic images by controlling their content, shape, size and colour, achieving the greatest visibility. However, the conscious use of graphic editors is somewhat modified, and non-standard conditions usually require appropriate mathematical training. Unfortunately, the geometric component in the mathematical training of the future computer science 
teachers is minimized; they get acquainted only with the fundamentals of analytical geometry [13].

The subject of the research is of current importance, which is explained by the need to optimize the graphic training of future teachers of computer science, who must master a high level of technical abilities, innovative, creative thinking, handle large amounts of information, and knowledge of the methodology of engineering. One of the ways to solve this problem is to justify the feasibility of using the project method in the process of studying the disciplines of the professional training unit [14].

\section{Materials and Methods}

The goal of the article is to analyze the possibility of optimizing the formation of graphic concepts for future teachers of computer science on the basis of a certain technique of using the project method. In order to achieve the stated goal, the following complex of methods is used in this study: theoretical methods - analysis of academic sources in the field of the research problem, which helped to determine the purpose of the study; empirical conversation, observation, survey, questioning, pedagogical experiment; statistical, determining the reliability of the results [15].

Within the framework of the concept of continuous education, an important pedagogical task in the preparation of modern computer science teachers becomes the formation of their constant need and readiness for graphic self-education. Therefore, one of the goals of training future specialists is to form and develop their graphic culture, which they should later educate their own students, developing their spatial thinking and creative abilities [16].

The cloud-oriented environment defined above was used for the development of component methodology designed for the instruction of prospective computer science teachers. In particular, we focused on the formation of professional and technical components of ICT competencies. These competencies reflect the professional qualifications of the future teacher. For computer science teachers, it is necessary to determine those competencies that are directly related to their profession and cover the content of the school ICT syllabus. The technology competencies of computer science teachers may be subdivided into two groups [17]:

- competence in basic technologies

- fundamental professional qualifications which for ICT teachers are considered as educational technologies (general teaching skills and resources of a computer science teacher);

- information technology competence, which determines the required learning outcomes of innovative information technologies and methods of their application in the teaching process. We used project work as the main method of instruction. A project is a task or problem which commonly engages a group of students and supplements traditional classroom studies. The notion of "project" encompasses different activities characterized by a number of common features:

- focus on achievement of specific purposes, certain results;

- coordination of interrelated actions;

- limited timing with a clearly defined beginning and end.

Project work is aimed at the formation of professional qualifications and skills, development of study habits and need for continuous learning, as well as the practical application of the acquired knowledge.

\section{Results and Discussion}

One of the components of technical thinking is a technical image, and hence in situations where it is activated in solving technical problems, it has a direct influence on the effectiveness of all stages of the solution process. Here a special kind of thinking is used - a visual one. The specificity of visual and imaginative thinking is managing the representations and images of objects; on the other hand - it is a stage in the development of human thinking in ontogenesis. It follows that in the process of solving a technical problem, the business entity must perceive and imagine images of technical objects specified in its condition [18].

The term "graphic training" is interpreted by the encyclopedia of education as the process of formation of the system of knowledge, abilities and skills necessary for reading and performing the graphic media of information transmission in which the system is based on the absorption of an organically interrelated set of learning material that shows in the graphic document all depiction sides of spatial and geometrical properties and shape of the depicted object [19].

For a competitive engineer-teacher of a computer profile, a deep knowledge of computer technologies and the ability to apply them in professional activities is not enough, and it is necessary to apply pedagogical methods for the analysis, synthesis and transfer of educational material, which is constantly updated and acquires a certain specificity in the conditions of continuous development of computer equipment and technologies. This integrated field of activity determines the features of the formation of graphic competence of the specialist [20].

The future teacher of computer technologies must deeply understand the value of school course of Computer Science in education, its role in future training, the principles of selection of its content, relationship to other school disciplines. They must master the technology of professional use of a PC and local network, study 
pedagogical software tools on the course of computer science, master various pedagogical technologies and methods of teaching computer science. Moreover, due to the vivid picture of technical equipment of schools, in the real practice of establishing the course of computer science, there is a wide variety of software in which the computer science teacher should easily navigate [21].

Therefore, while studying at a university, future teacher of computer science must establish subject matter expertise in ICT, which means understanding the ability to apply subject knowledge and skills in the information technology field and personal qualities for successful activity as a teacher, able to create and use modern means of ICT in class and for extracurricular activities.

The future teacher of computer sciences must have an idea about the purpose and capabilities of computer-aided design systems (CAD), which allows performing two-dimensional computer drawing and three-dimensional models. In the printing industry, architectural design, and industrial design in developed countries, computer graphics and information technologies have almost completely replaced traditional ones.

The most important components of the graphic culture of a specialist of any profile are the ability to carry out graphic task setting, design and build graphic models of the studied processes and phenomena, analyze graphic models using computer programs and interpret the results obtained, use computer graphics, the Internet, multimedia and other modern information technologies to analyze the studied processes and phenomena. At the same time, it is important to be able to organize, systematize, and structure graphic information, as well as to understand the principle of information modelling, how to represent graphic data and knowledge. For a modern teacher, it will be important to possess such skills as competent graphic design of visual materials for lessons, books, articles, scientific papers, Internet websites or an electronic textbook; the ability to create multimedia presentations or flash training videos on the computer screen and, use an interactive whiteboard, display them on a large screen $[22,23]$.

The goal of graphic training of teachers of computer technologies at the present stage is to give students knowledge, skills and abilities to prepare design documentation at all stages of its development, from the establishment of an idea to the technical implementation and operation of a technical object, using computer visualization tools for geometric modelling of products and processes. Graphic literacy is the foundation of graphic training for the future computer science teacher, which expands the scientific and professional horizons, develops spatial thinking and imagination, and activates cognitive and creative interest in the subjects that the students learn [24].

According to Kozak (2018), from the analysis of the system of training and conducted research in the related field it follows that graphic competence of an engineer-teacher of computer profile is an integral part of professional competence, which organically combines the responses to the queries of both technical and pedagogical component of the profession; a set of basic graphic knowledge and skills, and professional experience, combined with emotional intelligence (the ability to correctly deal with own emotions and respond to emotions of other people) together with creativity (the practical result of the creative inclinations) and self-improvement (development, mobility)[25].

The need for graphic training is determined by the fact that in the conditions of modern human labour activity, the most common means of transmitting information about objects of labour are graphic documents - drawings, diagrams, graphs, and so forth. At the present stage of development of society, the language of graphic images is becoming more widespread as a universal means of communication in many areas of activity, for which there are no language barriers.

An important indicator of the student's graphic culture should be his/her desire to use graphic information in various educational situations: if necessary, record new information, learn about the principle of operation of a technical object from technical documentation, convey the idea briefly and concisely in the form of a graphic image.

The previous studies outline the stages of forming the graphic culture of the future specialist in the process of training at the university: 1) simplistic graphic literacy provides the acquisition of initial graphic knowledge and skills necessary for further training at the university; 2) functional graphic literacy requires knowledge of fundamental provisions and implementation of links with other related disciplines; at this stage, the student is aware of the tasks of graphic training, outlines basic knowledge, applies algorithms of descriptive geometry to solve simple graphic problems; 3 ) graphic literacy is characterized by a significant amount of graphic knowledge and skills, ways of graphic process activities; 4) graphics professional competence requires a student's conscious use of graphic knowledge, abilities and skills that require knowledge of functional and constructive features of technical objects, graphic experience of professionally-oriented activities, free orientation in the environment graphic information technology; 5) graphic culture is characterized by indicators of level of formation of graphic culture of the future specialist .

The graphic activity of students can be referred to as a type of mental activity, the components of which can be further formed and developed. It is characteristic that graphic activity has the form of a two-stage process, at the first stage of which a graphic image is created in the student's imagination, and at the second stage the image is embodied in graphic constructions. The main features of graphic activity are the interaction of mental and practical actions that create an idea of the spatial properties of 
objects and conditional display on the plane or reproduction of spatial properties in the imagination on the basis of existing conventional images. The specifics of mental activity at the first stage of the process of graphic activity is the close interaction of mental operations, imaginative thinking and memory. The main function of graphic images is to reflect the spatial properties and relationships of objects, that is, to create a representation of an object.

In the process of training the future computer science teachers, engineering graphics can and must become a theoretical and practical foundation for performing professional tasks of geometric modelling. Informing students about the professional content of graphic training has a feedback function, which consists of motivating modern persons, who are pragmatic-oriented towards expanding their own knowledge. The project method can be an effective tool in such circumstances.

Starting preparation for the lesson, which must form a certain graphic concept in the student's mind, special attention should be paid to tasks related to the subject of future professional activities of students. Addressing this type of problem is based on the psychological principle of "forward-looking reflection".

How to start the work if there is a challenge to choose a graphic task for studying a particular topic, and it has been decided to analyze this issue through the prism of project technology?

Design is the process of creating a prototype of a future product with the desired properties and developing ways of its production. From whimsical desires, empty dreams and unfounded fantasies, a project plan differs in that it contains a rational justification and a specific method (technology) for its practical implementation.

According to Podpokrovny et al. (2018), design in construction and engineering is the development of the project, engineering and other technical documentation intended for capital construction (of any object), the creation of new types and samples of industrial products. During the design process, technical and economic calculations, diagrams, graphs, notes of explanations, layouts, specifications, estimates, calculations, and descriptions are made. Project is a set of specified documentation and materials (of a certain composition). The project of a certain capital construction object (enterprise, building, structure), for example, can be individual or typical. In the development of individual projects, standard designs of architectural and mounting parts and standard design solutions are widely used. Design of new types and samples of machines, equipment, devices, appliances and other products of various industries (design) is the development of initial data (drawings, specifications, technical conditions of assembly processes, settings, costs, design documentation etc.) necessary for the production and subsequent operation of products. Normalized parts, unified nodes, and aggregates are widely used in this process [26].

Work on a project involves the implementation of certain stages: the project justification, the search stage, the technological stage, and the final stage. There are certain rules and requirements for information arrangement for each stage of the project.

The content of such concepts as "project", "project activity", "design stages", "design methods" is known to students from the school years.

Therefore, work on the implementation of project technology in the process of graphic training of future teachers of computer science should begin with the answer to the question: what benefit will the work performed have for the future professional activity of the student?

When choosing a graphic document or image, it is important to focus on the items that will be used in the conditions of performing professional tasks.

Thus, the work should begin with the formulation of the project's goal and task, justification of its importance, and definition of the project's theme.

The project goal is a model of the desired practical end result that should be achieved as a result of the project implementation.

To establish the goal of the project, it is possible to follow the simple scheme:

1. Select one of the following words: perform, develop, create, improve, learn to perform, draw, etc.

2. Add a name to the graphic document.

3. Add one or more of the phrases that answer the question:

- What device will be used to perform the work, on what media? (for example, "production with using CAD", "A1 format")

- What is the goal of a graphic document? (for example, "to design the technological process")

- For whom will the graphic document be directed? (for example, "for process engineers")

- What type of graphic document will be used? (for example, "sketch")

- What is the usefulness of a graphic document? (for example, "to organize the production process")

For example:

The goal of a graphic document is "To develop a design and perform a comprehensive orthographic drawing of the server cabinet for an enterprise."

After the formulation of the project goal, it is necessary to proceed to define specific tasks to be solved in accordance with the goal.

Project tasks are all sequential stages of the graphic document performance from beginning to end.

In order to define the project tasks, it is necessary to consistently answer the questions: "What should be done to achieve the project goal?"

As a rule, tasks are set out (to develop..., to refine ..., to get to know ..., to learn ..., to master ..., to define ..., to 
choose ..., to select ..., to conduct ..., to improve ..., to analyze, etc.).

An explanation of the necessity and usefulness of completing a certain project is called "justification" for the relevance of the project.

As an example, it can be seen the justification for the relevance of the project "Drawing of a mounted server cabinet".

Many companies use server hardware to create an internal network. Such devices require safe and secure placement. Often the size of server rooms does not allow to install the necessary devices, so it is reasonable to produce a non-standard mounted server cabinet. Unlike server cabinets of mass production, this cabinet can be fixed to the wall in the most convenient place using mounting plates, so that room space is saved. The production of such a cabinet is impossible without a preliminary drawing of this product.

The main criteria that determined the choice are:

- Practicability;

- Manufacturability;

- Aesthetic qualities.

When determining the goal and tasks of the project, the knowledge and skills that students have gained in classes in other professionally-oriented disciplines must be exploited to its maximum.

Great importance in product design should be given to the requirements of the technologies used in the project implementation process. In particular, it is manufacturability, cost-efficiency, usability, safety, and environmental friendliness. Students also have got acquainted at school with the listed requirements that must be considered in the product manufacture process.

A design object that the student will be interested in working on should be selected.

The time spent on the completing of the graphic document should also be taken into consideration. It is necessary to conduct a detailed analysis of how much each lesson lasts and how much time is needed for each stage of the drawing.

After the goal and tasks of the project were defined, the choice was justified; it is necessary to make a plan for project implementation.

This plan is called the design stage. To formulate the plan, it is required to:

1. Collect and process information necessary for project implementation from literature and other sources;

2. Study the technology of graphic document performance, make calculations, and solve other important tasks;

3. Prepare equipment for the performance of a graphic document, own workplace;

4. Determine how to present the project results, that is, in what form the report will be presented (text description of the results, diagrams, presentation, photos of the product or object, audio or video recording of observations or stages of production);

5. Set the criteria for evaluating the final result and the work process (how the evaluation will be conducted);

6. Distribute tasks and responsibilities among the team's students (if it is a group or collective project).

At the stage of determining the shape of the product and its design, it is possible to apply the method of analogies (similarity method), a method of combination that students got familiar with at school.

To improve the properties of a technical product, as well as to design a new product with interesting, wider possibilities, sometimes at the expense of design changes, the method of focal objects, which students studied in 7 th grade at school, can be of help.

To organize the collected information for the project implementation, it is advisable to create a bank of ideas and proposals. Students were also introduced to the structure of the bank idea and its use algorithm at school. The combinatorial method, which is already familiar to students, will be extremely useful in providing a creative approach to the process of product shape formation.

In order to plan the work on the implementation of the graphic document, students can be offered samples of drawings of the general type of products that consist of several parts, asking for an explanation of whether the provided information is enough to immediately start manufacturing this complex product?

A general drawing is a document that defines the product design, the interaction of its components, and explains how the product works.

The general drawing must contain:

- product images, text parts, and captions that are necessary to understand the design of the product, the interaction of its components, and the principle of operation;

- title and designation of the component parts of the product;

- dimensions and other data that are applied to the image;

- scheme, if necessary;

- technical specifications of the product, if it is necessary for the convenience of comparing options according to general drawings.

The titles and designations of the components of the product in the general drawings are specified in one of the following ways:

- on the leader lines;

- in a spreadsheet placed on the same sheet as the product image;

- in a spreadsheet made on separate sheets of A4 format as subsequent sheets of the general drawing.

The spreadsheet usually consists of columns: "Position", "Designation", "Quantity”, “Additional information”. 
The main purpose of planning is to achieve maximum productivity with minimal time, labour, and equipment.

The work plan for the implementation of the project "Drawing of a mounted server cabinet" includes:

1. Determining the shape and size of the product (part), the order of collection of individual parts, as well as the material from which these parts are made.

2. Determining the minimum number of images required.

3. Selecting the equipment for performing a graphic document.

4. Selecting how to control the quality of the graphic document that is being performed.

5. Preparing the workplace for work.

\section{Performing a Graphic Document}

At the final stage of the project, it is discussed and defended. The performance is usually scheduled for 5-7 minutes. In the process of preparing for the presentation, it is necessary to compile a project defence plan that should contain:

- creative project theme;

- information on the purpose of the creative project;

- argument for choosing a theme;

- justification of the need for the product;

- information on the tasks set: constructive, technological, environmental, aesthetic, economic and marketing;

- a brief historical background on the project topic (ways of displaying products in the past and at present, materials used, etc.);

- information on the progress of the project (type and quantity of equipment used for performing the graphic document, the technological operations applied during its execution, resolution of problems encountered during practical work, the economic feasibility of the graphic document (based on the analysis of the market price equivalent, the estimated cost of the document and the real costs);

- information on solving environmental problems;

- conclusions on the project theme (achievement of the set goal, results of solving the set tasks, possible modernization of the document, what is learned).

The presentation of the completed graphic document must be conducted, as well.

At the project defence after the speech, the presented audience can ask questions and express their opinions. Questions and explanations should concern the nature of the project work.

\section{Conclusions}

Project activity can be an incentive for activating brainwork, developing cognitive and social activity of a modern student. Project activity increases the interest in learning, expands the horizons, and makes it possible to consciously receive and apply the acquired knowledge independently. Students acquire the skills to search for necessary information and process it, acquire research skills, get the opportunity to navigate the information space, cooperate with the teacher and with each other, justify their vision of a particular issue, have the opportunity to discuss and make independent decisions. In other words, the project method acts as a set of search, research, and problem methods.

In the project activity combined with the tasks of graphic training, future teachers of computer science comprehend the entire technology of solving problems from the problem statement to the presentation of the results. The relevant areas of further development of the problem are the study of the psychological and physiological foundations of graphic activity using computer-aided design systems and their influence on the formation of hierarchical relations between the semantic units of graphic concepts, which are studied by future teachers of computer science in higher education institutions.

\section{REFERENCES}

[1] Ansimova, O. K. (2017). CONDITIONAL GRAPHIC IMAGES IN THE TRAINING RUSSIAN AS FOREIGN LANGUAGE (1ST CERTIFICATION LEVEL). In 6th International Scientific-Practical Conference" Education Transformation Issues" SCIEURO (pp. 33-40).

[2] Jaafar, N. M., \& Thang, S. M. (2020). Dependency on Verbal Versus Graphic Representations among Second Language Learners When Reading Illustrated Expository Materials. Universal Journal of Educational Research, 8(2), 454-459.

[3] Alhajri, S. (2016). The Effectiveness of Teaching Methods Used in Graphic Design Pedagogy in Both Analogue and Digital Education Systems. Universal Journal of Educational Research, 4(2), 422-425.

[4] Belavina, T., Gorskaya, T., \& Goulkanyan, M. (2020, July). Engineering and computer graphics for effective training in a construction university. In IOP Conference Series: Materials Science and Engineering (Vol. 890, No. 1, p. 012173). IOP Publishing.

[5] Popov, L. M., Puchkova, I. M., \& Ustin, P. N. (2016). Formation of psychological readiness for professional activity: Competence approach. International Electronic Journal of Mathematics Education, 11(4), 819-827.

[6] Ching, Y. H., Hsu, Y. C., \& Baldwin, S. (2018). Developing computational thinking with educational technologies for young learners. TechTrends, 62(6), 563-573.

[7] Yusnita, Y., Eriyanti, F., Engkizar, E., Anwar, F., Putri, N. 
E., Arifin, Z., \& Syafril, S. (2018). The Effect of Professional Education and Training for Teachers (PLPG) in Improving Pedagogic Competence and Teacher Performance. Tadris: Jurnal Keguruan dan Ilmu Tarbiyah, 3(2), 123-130.

[8] Dusbayeva, N., Valijonov, S., \& Hamidhonov, K. (2019). Innovative Activities As an Object Of Investments. Мировая наука, (4), 33-35.

[9] Xavier, G., \& Dias, C. M. (2019). Gamification for Graphic Education: A Case Study on Innovative Methodology. In Videogame Sciences and Arts: 11th International Conference, VJ 2019, Aveiro, Portugal, November 27-29, 2019, Proceedings (Vol. 1164, p. 208). Springer Nature.

[10] Песецкая, Т. И. (2019). Using Means of Multimedia for Teaching International Students Geometrical Issues of Computer Graphics in English. In Образование. Наука. Культура (рp. 450-451).

[11] Nayar, P. K. (2018). Literature (Now) Contains Graphic Language: Adaptation, Visualization and Transmedia Texts. Rupkatha Journal on Interdisciplinary Studies in Humanities, 10(1).

[12] Itelson, L. B. (2000). Lectures on general psychology. Mn.: Harvest.

[13] Ramsey, C. G. (2007). Architectural graphic standards. John Wiley \& Sons.

[14] Новак, O. (2019). USING THE PROJECT METHOD IN PROFESSIONAL TRAINING OF FUTURE LECTURERS IN PROFESSIONAL EDUCATION (OCCUPATIONAL SAFETY AND HEALTH) THROUGH THE COURSE ON PEDAGOGY OF HIGHER EDUCATION. Society. Document. Communication, (6/2), 151-170.

[15] El Hammoumi, S., Zerhane, R., \& Janati Idrissi, R. Pedagogical Innovation on Interactive Graphic Animations: Case Study of Synaptic Transmission-1st Year Bachelor's Degree, Life and Earth Sciences, Morocco.

[16] Bredniova, V. P. (2016). On the improvement of the methodology of engineer staff's graphic training on the basis of optimization of psychological and pedagogical approaches.
[17] Yerdelen-Damar, S., Boz, Y., \& Aydın-Günbatar, S. (2017). Mediated effects of technology competencies and experiences on relations among attitudes towards technology use, technology ownership, and self efficacy about technological pedagogical content knowledge. Journal of Science Education and Technology, 26(4), 394-405.

[18] Knibb, N. (2019). The Margin of Elegance: How the university art gallery provides vital space for careful, inquisitive, and imaginative postsecondary learning.

[19] Alvarez, F. J. A., Parra, E. B. B., \& Tubio, F. M. (2017) Improving graphic expression training with 3D models. Journal of Visualization, 20(4), 889-904.

[20] Bogoviz, A. V., Gulyaeva, T. I., Semenova, E. I., \& Lobova, S. V. (2019). Transformation changes in the system of professional competences of a modern specialists in the conditions of knowledge economy's formation and the innovational approach to training. In Industry 4.0: Industrial Revolution of the 21st Century (pp. 193-200). Springer, Cham.

[21] Weatherhead, A. (2018). Teachers' Pedagogical Design Capacity for Embedded Formative Assessment: A Case Study of Master Teachers Implementing a New Practice (Doctoral dissertation, University of Pittsburgh).

[22] Bylinskii, Z., Kim, N. W., O'Donovan, P., Alsheikh, S., Madan, S., Pfister, H., ... \& Hertzmann, A. (2017, October). Learning visual importance for graphic designs and data visualizations. In Proceedings of the 30th Annual ACM symposium on user interface software and technology (pp. 57-69).

[23] Musalimov, T., Tanirbergenova, A., Bazarbaeva, K., Ispandiyarova, A., Taspolatova, R., Lipina, S., ... \& Shakhmetova, D. (2017). Graphic culture development in specialists in the field of technical sciences. Espacios, 38(48), 28-28.

[24] Kozak YuYu. Graphic competence in training of future engineers-teachers of computer sciences. Vinnytsia: VDPU. 2018 .

[25] Podpokrovny SV, Ponuliak Dya, Garkushevsky VS. Modern processes of product design in the system of organization and production design engineering. Vinnytsia: VDPU. 2018. 